\title{
Cost-effectiveness of formoterol and salbutamol as asthma reliever medication in Sweden and in Spain
}

\author{
B. LINDGREN, ${ }^{1}$ M.R. SEARS,${ }^{2}$ M. CAMPBELl, ${ }^{3}$ C. VILlASANTE, ${ }^{4}$ S. HUANG, ${ }^{5}$ A. LINDH, ${ }^{6}$ \\ W. PETERMANN, ${ }^{7}$ K. SVENSSON ${ }^{8}$ F. BERGGREN, ${ }^{8}$ R.A. PAUWELS ${ }^{9}$, ON THE BEHALF OF THE \\ RELIEF STUDY INVESTIGATORS \\ Lund University Centre for Health Economics, ${ }^{1}$ Lund University, Lund, Sweden, Firestone Institute for Respiratory Health, ${ }^{2}$ \\ St Joseph's Healthcare and McMaster University, Hamilton, Canada, Department of General Practice, ${ }^{3}$ University of Glasgow, \\ Glasgow, Scotland, Department of Respiratory Diseases, ${ }^{4}$ Hospital Universitaro La Paz, Madrid, Spain, Pulmonary Department, ${ }^{5}$ \\ Ruijin Hospital, Shanghai Second Medical University, Shanghai, China, Husläkarna Österåker, ${ }^{6}$ Åkerberga, Sweden, Department \\ of Internal Medicine, ${ }^{7}$ Brüderkrankenhaus, Paderborn, Germany, Clinical Science, ${ }^{8}$ AstraZeneca RひD Lund, Lund, Sweden, \\ Department of Respiratory Diseases, ${ }^{9}$ University Hospital, Ghent, Belgium
}

\section{SUMMARY}

This study aimed to evaluate the cost-effectiveness of formoterol $\left(\mathrm{Oxis}^{\circledR}\right.$ ) Turbuhaler $^{\circledR} 4.5 \mu \mathrm{g}$ and salbutamol $200 \mu \mathrm{g}$ as reliever medications in Sweden and Spain. The study used data on effectiveness (exacerbations and symptom-free days) and resource utilisation from an open, 6-month, parallel-group, multicentre randomised trial with 18,124 asthma patients in 24 countries. Country-specific unit costs for Sweden and for Spain were used to transform resource utilisation data into costs. Total healthcare costs were not significantly different between formoterol and salbutamol dry powder inhalers in Sweden, whereas in
Spain, the healthcare costs were $20 \%$ higher for formoterol vs. salbutamol pressurised metered dose inhalers. Total healthcare costs increased with disease severity, defined according to the Global Initiative for Asthma guidelines. Compared with salbutamol, formoterol produced statistically significant improvements in effectiveness, less reliever and maintenance medication usage, reduced healthcare resource utilisation, with no increase or a limited increase in healthcare cost.

Keywords: Asthma; reliever; formoterol; salbutamol; costeffectiveness; Sweden; Spain; RELIEF

(c) 2005 Blackwell Publishing Ltd

\section{INTRODUCTION}

Treatment guidelines for asthma recommend a rapid-acting bronchodilator as reliever medication (1,2). Traditionally, salbutamol and terbutaline with a rapid onset of action are used as relievers in asthma, but they have the drawback of a relatively short duration of action (4-6h). Formoterol is a bronchodilator with both rapid onset and long duration of action $(>12 \mathrm{~h})(3,4)$. Formoterol $\left(\mathrm{Oxis}^{\circledR}\right.$ ) Turbuhaler $^{\circledR}$ (AstraZeneca R\&D, Lund, Sweden) has been proved to be more effective and as well tolerated as salbutamol (5). However, the prices of short-acting bronchodilators are much lower than the price of formoterol. Thus, the added benefits of formoterol in terms of improved asthma control and potentially lower costs for healthcare utilisation will have to be balanced against its higher price.

\section{Correspondence to:}

Björn Lindgren, Lund University Centre for Health Economics (LUCHE), Box 705, SE-220 07 Lund, Sweden

Tel.: +46462220659

Fax: +46462220651

Email: bjorn.lindgren@luche.lu.se
There is a clear incentive to adopt treatment concepts shown to improve asthma control (6), which are also associated with reduced consumption of healthcare resources (7). It has already been established that formoterol Turbuhaler ${ }^{\circledR}$ significantly reduced the number of severe exacerbations, compared with terbutaline, resulting in a favourable costeffectiveness profile $(8,9)$. To be able to recommend the general adoption of formoterol Turbuhaler ${ }^{\circledR}$ as reliever medication, the safety, clinical benefit and cost-effectiveness of formoterol need to be demonstrated in a broader range of patients than that investigated previously (9). Recent developments of health economic guidelines (10) support the use of real-life cost-effectiveness studies for allocating resources, rather than studies with narrow inclusion criteria, and a review (11) recommended studies that analyse the cost-effectiveness of treatment options in all degrees of asthma severity.

The aim of the present study was to evaluate cost and effectiveness from a healthcare perspective of the use of formoterol Turbuhaler ${ }^{\circledR} 4.5 \mu \mathrm{g}$ and salbutamol $200 \mu \mathrm{g}$ as reliever medication in an asthma population aged 6 years or older with a wide range of asthma severity and taking various maintenance medications. 
The cost-effectiveness analysis was conducted for Sweden and Spain. These countries were chosen because of their differing traditions of bronchodilator delivery treatment patterns - over $80 \%$ delivered by pressurised metered dose inhalers (pMDI) in Spain, whereas in Sweden, almost $80 \%$ are delivered by dry powder inhalers (DPIs). For the Swedish analysis, Oxis ${ }^{\circledR}$ Turbuhaler $^{\circledR} 4.5 \mu \mathrm{g}$ was compared with salbutamol DPI in Sweden (Ventolin ${ }^{\circledR}$ Diskus $200 \mu \mathrm{g}$ ) and salbutamol pMDI (Ventolin ${ }^{\circledR}$ pMDI $100 \mu \mathrm{g}$ with two actuations per dose) in Spain.

\section{MATERIALS AND METHODS}

Total healthcare cost and effectiveness were evaluated over a 6-month period. As the healthcare payer perspective was taken, only healthcare costs (such as study medication, maintenance medication for asthma, hospitalisations, emergency treatment and other healthcare contacts) were included. Thus, productivity costs were not included. Effectiveness was measured as percentage of symptom-free days, rate of mild exacerbations, rate of severe exacerbations and number of days with inability to conduct normal activities due to asthma.

\section{Clinical Study Design}

This economic evaluation was based on the REal-LIfe EFfectiveness of Oxis Turbuhaler as needed in asthmatic patients (RELIEF) study, an open, 6-month, randomised, parallelgroup study conducted at 1139 centres in 24 countries (5). The RELIEF study included patients with asthma of any severity, aged 6 years or older, who used or were candidates for using a reliever medication. For information on patient characteristics, see Table 1. Any asthma medication, except other reliever medication, and any change in prescribed medication was allowed. Patients were randomised to receive either formoterol (Oxis ${ }^{\circledR}$ ) Turbuhaler ${ }^{\circledR} 4.5 \mu \mathrm{g}$ or salbutamol
$200 \mu$ g. Salbutamol was delivered via pMDI or DPI $\left(\right.$ Ventolin $^{\circledR}$, Ventoline $^{\circledR}$, Aerolin $^{\circledR}$, Salbuvent ${ }^{\circledR}$ and Inspiryl $\left.{ }^{\circledR}\right)$.

Patients attended the clinic at study entry and after 1, 3 and 6 months of treatment. The patients used a notebook to register the number of inhalations of study medication and the number of days with asthma symptoms during the previous 2 weeks before the clinic visits. This design was chosen in order to interfere as little as possible with the patient's usual daily life activities. Healthcare contacts due to asthma, the number of days when the patient was incapable of conducting usual activities for six or more hours of the day due to asthma and changes in regular asthma medication were recorded for the entire study duration. During the visits, the investigator recorded the number and duration of hospitalisations, number of emergency treatments, other healthcare contacts, increases in maintenance medication and courses of oral corticosteroids due to deterioration in asthma that occurred in the preceding study period.

Asthma maintenance treatment was recorded twice, at study entry visit and at the last visit after 6 months. At study entry, four asthma medication levels were identified (as proxies for disease severity) - (i) intermittent: no maintenance; (ii) mild: inhaled corticosteroids $<500 \mu \mathrm{g} / \mathrm{day}$; (iii) moderate: inhaled corticosteroids $>500 \mu \mathrm{g} /$ day or $500-800 \mu \mathrm{g} /$ day and longacting bronchodilator; and (iv) severe: inhaled corticosteroids $>800 \mu \mathrm{g} /$ day and long-acting bronchodilator (1).

The primary safety endpoints were asthma- and non-asthmarelated serious adverse events and discontinuations due to adverse events. The primary clinical endpoint was time to first exacerbation, and the secondary endpoints included severe exacerbations, symptoms and reliever-medication use.

\section{Effectiveness Variables}

A severe exacerbation was defined as one of the following asthma-related events: a hospitalisation, an emergency treatment

Table 1 Demographics and patient characteristics (adapted from Pauwels et al.) (5)

\begin{tabular}{lccc}
\hline Characteristics & Formoterol $(n=9064)$ & Salbutamol $(n=9060)$ & Total $(n=18,124)$ \\
\hline Gender (\% female) & 57 & 58 & 57 \\
Race $(n)$ & & & 13,817 \\
$\quad$ Caucasian & 6915 & 6902 & 2866 \\
Oriental & 1438 & 1428 & 1441 \\
Other & 711 & 730 & $39(4-91)$ \\
Age (years), mean (range) & $39(5-91)$ & $39(4-91)$ & $1696(9 \%)$ \\
Age groups & & & $1594(9 \%)$ \\
Children: $\leq 11$ years & 847 & 849 & $12,994(72 \%)$ \\
Adolescents: $12-17$ years & 790 & 804 & $1840(10 \%)$ \\
Adults: $18-64$ years & 6526 & 6468 & \\
Elderly: $\geq 65$ years & 901 & 939 & $2823(16 \%)$ \\
Severity judged by asthma medication levels* & & $6313(35 \%)$ \\
$\quad$ Intermittent & 1427 & 1396 & $6281(35 \%)$ \\
Mild & 3178 & 3135 & $2707(15 \%)$ \\
Moderate & 3127 & 3154 & 1375 \\
$\quad$ Severe & 1332 & & \\
\hline
\end{tabular}


or a course of oral corticosteroids for at least 5 days. A mild exacerbation was defined as an increase in maintenance medication due to asthma. Severe and mild exacerbations were also aggregated in the total number of exacerbations. The numbers of symptom-free days were recorded during 2 weeks prior to visits 2, 3 and 4, and then extrapolated for the entire duration between two study visits. The number of days with inability to conduct normal activities (work, etc.) due to asthma for at least $6 \mathrm{~h}$ was recorded. For children under the age of 12 years, the number of days that their parent or legal guardian was unable to conduct normal activities due to the child's asthma was recorded.

\section{Resource Utilisation Variables and Unit Costs}

The following healthcare resource utilisation items were recorded in case reports and used to estimate cost: the number of days hospitalised, the number of emergency treatments and the number of other contacts with healthcare services. Due to the size of the study, the number of questions in the case report form had to be minimised. Thus, a few broad questions had to be compiled, for example, the question concerning other healthcare contacts, which encompassed a number of individual resource utilisation items (physician visit, nurse visit, house-call by a physician, house-call by a nurse, phone-call to a physician or a nurse). The data recorded in the group 'other healthcare contacts' were assumed to have the same distribution as the resource variables in the Oxis ${ }^{\circledR}$ and Pulmicort ${ }^{\circledR}$ Turbuhaler $^{\circledR}$ in the Management of Asthma study, where this group of variables was analysed in a similar way (12).

Information on the patient's asthma maintenance medications was recorded at study entry and at the last visit. Medications used, their form of administration and daily dosages were all recorded in detail. The use of study medication was recorded 2 weeks before visits and after 1, 3 and 6 months.

Resource utilisation data for the RELIEF study as a whole were transformed into costs by using country-specific unitcost data. Unit costs for Sweden and Spain were verified based both on information given by local country experts and on official statistics (Table 2).

\section{Cost and Effectiveness}

Data on each item of resource utilisation was obtained from the clinical study and used to obtain a cost estimate for the resources used, by multiplying the number of units by a defined unit cost. Cumulative costs were estimated for each cost item based on cost per day estimates. Exacerbations, as an effectiveness variable, were estimated as the rate per year, and symptom-free days were estimated as a percentage.

\section{Statistical Issues}

Cost and effectiveness data were initially estimated for individual data on a daily basis for each treatment. These daily
Table 2 Unit costs in year 2000 prices

\begin{tabular}{|c|c|c|}
\hline Resource utilisation item & Sweden $(€)$ & Spain $(€)$ \\
\hline \multicolumn{3}{|l|}{ Inhaled corticosteroids (mg) } \\
\hline Budesonide pMDI & 1.569 & 1.013 \\
\hline Budesonide DPI & 1.029 & 1.013 \\
\hline Fluticasone pMDI & 1.991 & 1.904 \\
\hline Fluticasone DPI & 1.991 & 1.904 \\
\hline Beclometasone pMDI & 0.707 & 0.459 \\
\hline Beclometasone DPI & 0.815 & 0.459 \\
\hline Other pMDI & 0.707 & 0.459 \\
\hline Other DPI & 0.815 & 0.459 \\
\hline \multicolumn{3}{|c|}{ Long-acting $\beta_{2}$-agonist maintenance (days) } \\
\hline Formoterol & 1.018 & 1.114 \\
\hline Salmeterol & 1.146 & 1.345 \\
\hline LTRA: Singulair/Accolate (days) & 1.319 & 1.671 \\
\hline \multicolumn{3}{|l|}{ Cromoglycates (days) } \\
\hline pMDI & 1.981 & 0.591 \\
\hline Others & 1.321 & 0.591 \\
\hline Nedocromiles (days) & 1.321 & 1.305 \\
\hline Oral $\beta_{2 \text {-agonist, Xanthines (days) }}$ & 0.356 & 0.250 \\
\hline Oral steroids maintenance $10 \mathrm{mg} /$ day & 0.204 & 0.103 \\
\hline Oral steroids exacerbation $30 \mathrm{mg} /$ day & 0.611 & 0.231 \\
\hline \multicolumn{3}{|l|}{ Study drug (doses) } \\
\hline Formoterol Turbuhaler $^{\circledR}$ & 0.414 & 0.423 \\
\hline Salbutamol pMDI & 0.050 & 0.042 \\
\hline \multicolumn{3}{|l|}{ Hospital } \\
\hline Hospitalisation (days) & 368.515 & 302.634 \\
\hline Emergency treatment & 247.546 & 94.503 \\
\hline \multicolumn{3}{|l|}{ Other Healthcare contacts } \\
\hline Visit to physician & 152.552 & 25.381 \\
\hline Visit to nurse & 40.363 & 12.110 \\
\hline House-call physician & 104.750 & 22.670 \\
\hline House-call nurse & 41.583 & 16.684 \\
\hline Phone-call physician/nurse & 6.829 & 7.753 \\
\hline Pharmacy contact & 3.902 & 0.000 \\
\hline \multicolumn{3}{|l|}{ Incapability days } \\
\hline Employed or house-person & 159.503 & 79.838 \\
\hline Unemployed & 91.092 & 0.000 \\
\hline
\end{tabular}

DPI, dry powder inhaler; LTRA, leukotriene receptor antagonist; pMDI, pressurised metered dose inhaler.

rates were then normalised to 1 person-year by multiplying daily rates by 365.25 .

Differences in costs and effectiveness were tested with a parametric $t$-test. Cost-effectiveness ratios and confidence intervals (CIs) were estimated with a non-parametric bootstrap approach; the Bca method by Efron and Tibshirani (13) was applied.

In clinical studies, it is well established to aggregate outcome measures across countries. Even though patient management, resource use and unit cost (prices) can certainly be assumed to vary considerably both between and within countries, this study was not specifically designed to investigate such differences. However, it should be noted that there was no statistically significant difference in exacerbations (a known cost 
driver) between geographical regions, i.e. a subgroup analysis on exacerbations provided similar outcomes across: 'Western' (Western Europe and Canada), 'Eastern' (Asian countries) and 'Other' (Eastern Europe, South Africa and Mexico) regions.

Furthermore, this study aimed to detect differences between the two treatment groups, and the bias in a relative difference might be smaller than the bias for a difference in absolute numbers (14). Hence, the evaluation employed pooled resource utilisation data in accordance with the clinical approach. Cost data, however, are always country specific by definition, so the relevant pooled resource utilisation data were multiplied by the corresponding country-specific unit cost. Thus, the healtheconomics results would also be country specific.

\section{RESULTS}

Of the 18,124 randomised patients in the RELIEF study, 17,618 were eligible for the health-economics analysis (formoterol $n=8786$, salbutamol $n=8832$ ). At the study entry, $76 \%$ of patients were being treated with inhaled corticosteroids and $31 \%$ with an inhaled long-acting bronchodilator.

The clinical results showed that using formoterol as reliever medication improved asthma control in comparison with salbutamol, and that there were no safety issues (5). The reduction in maintenance of asthma medication from study entry to last study visit, according to asthma medication levels defined by the Global Initiative for Asthma guidelines (1), was significantly greater in the formoterol group than in the salbutamol group $(\mathrm{p}=0.001)$. The average number of inhalations of study medication per day was also significantly lower in the formoterol group compared with the salbutamol group (1.30 vs. $1.51 ; \mathrm{p}<0.0001)$.

The effectiveness results presented in Table 3 show a consistent pattern of improvements in favour of formoterol over salbutamol across a range of patient outcome measures. The yearly rate of exacerbations and the percentage of symptomfree days were both significantly in favour of formoterol. The largest improvement in effectiveness, in percentage terms, was seen for the reduction in the rate of severe exacerbations. Healthcare resource utilisation results are presented in Table 4. All of the individual resource utilisation variables were lower in the formoterol group than in the salbutamol group; the largest differences were found for the number of hospital days and the number of emergency treatments.

The results on total daily healthcare costs generated from the resource utilisation are summarised in Table 5. Although the cost of the study drug was higher in the formoterol group, the additional cost of formoterol was partly offset by reductions in cost resulting from lower utilisation of other asthma medication and of other healthcare resources for both countries. Because of the lower price of salbutamol pMDI than DPI, a comparatively lower part of the study drug costs was offset by the cost of emergency treatments and other healthcare contacts, such as physician visits, for Spain than for Sweden (see Figure 1). Thus, for Sweden, the 6\% difference in total daily healthcare cost was not statistically significant, but in Spain healthcare cost was estimated to be $20 \%$ higher $(p<0.05)$ with formoterol treatment compared with the cheapest salbutamol pMDI.

The total healthcare costs are presented in Figure 2, for all patients as well as for patients according to disease severity. Differences in total healthcare costs according to asthma severity were not significantly different between the two treatment groups for intermittent, mild and severe asthma patients in Sweden, although a difference was observed for moderate patients. Further, it is interesting to note that for Sweden, the healthcare costs were even numerically lower for formoterol in the severe patient group. For Spain, formoterol had significantly higher cost for all severity groups, except for severe patients.

Table 3 Effectiveness measures for the analysis $(n=17,618)$

\begin{tabular}{lccrc}
\hline Variable & Formoterol $\left(\right.$ Oxis $\left.^{\circledR}\right)$ & Salbutamol & Percentage difference & p-value \\
\hline Severe exacerbations/year & $0.63 \pm 2.69$ & $0.74 \pm 4.00$ & -15 & 0.034 \\
Mild exacerbations/year & $0.78 \pm 2.19$ & $0.90 \pm 2.29$ & -13 & $<0.001$ \\
Total exacerbations/year & $1.41 \pm 3.91$ & $1.64 \pm 5.06$ & -14 & $<0.001$ \\
Symptom-free days (\%) & $58.82 \pm 33.33$ & $57.20 \pm 34.30$ & +3 & 0.0015 \\
Number of days with inability/year & 2.27 & 2.51 & -10 & 0.17 \\
\hline
\end{tabular}

Table 4 Healthcare resource utilisation by items: mean number normalised to 1 patient-year with differences presented as percentages $(n=17,618)$

\begin{tabular}{lllll}
\hline Variable & Formoterol $\left(\right.$ Oxis $^{\circledR}$ ) & Salbutamol & Percentage difference & p-value \\
\hline Days hospitalised & 0.22 & 0.30 & -27 & 0.23 \\
Emergency treatments & 0.29 & 0.36 & -20 & 0.14 \\
Courses of oral glucocorticosteroid & 0.30 & 0.34 & -12 & 0.023 \\
Other healthcare contacts & 1.34 & 1.45 & -8 & 0.15 \\
\hline
\end{tabular}


Table 5 Mean total daily healthcare costs by resource item (using year 2000 prices), according to pooled resource utilisation data for all countries and country-specific prices in Euro $(€)$ for Sweden and Spain

\begin{tabular}{|c|c|c|c|c|}
\hline \multirow[b]{2}{*}{ Variable } & \multicolumn{2}{|c|}{ Sweden $(€ 1=S E K$ 8.45) } & \multicolumn{2}{|c|}{ Spain $(€ 1=E S P$ 166.4) } \\
\hline & $\left.O x i i^{(}\right)$ & Ventolin $^{\circledR}$ DPI & $O x i i^{\circledR}$ & Ventolin $^{\circledR} p M D I$ \\
\hline Study drug & 0.54 & 0.19 & 0.55 & 0.07 \\
\hline Asthma medication & 1.17 & 1.22 & 1.16 & 1.21 \\
\hline Hospitalisation & 0.23 & 0.31 & 0.19 & 0.25 \\
\hline Emergency treatment & 0.20 & 0.24 & 0.08 & 0.09 \\
\hline Other healthcare contacts & 0.35 & 0.38 & 0.06 & 0.07 \\
\hline Total daily healthcare cost & 2.49 & 2.35 & 2.03 & $1.69^{*}$ \\
\hline Difference in healthcare costs (\%) & \multicolumn{2}{|c|}{6} & \multicolumn{2}{|c|}{$20^{*}$} \\
\hline
\end{tabular}

DPI, dry powder inhaler; pMDI, pressurised metered dose inhaler.

${ }^{*}$ Significant difference between Oxis ${ }^{\circledR}$ and Ventolin ${ }^{\circledR}$ pMDI $(\mathrm{p}<0.05)$.

The incremental cost-effectiveness ratios were estimated as the total daily healthcare cost per avoided severe exacerbation. For Sweden, the total daily healthcare cost per avoided severe exacerbation was $1.38 € /$ day (CI $0.26-6.13$; $504 € /$ year, CI 95-2239) and the total daily healthcare cost per any avoided exacerbation was $0.62 € /$ day (CI $0.11-1.57 ; 140 € /$ year, CI 40-573). For Spain, the total daily healthcare cost per avoided severe exacerbation was $2.98 € /$ day (CI 1.57-9.69; $1088 €$ /year, CI 537-3559) and the total daily healthcare cost per any avoided exacerbation was $1.34 € /$ day (CI 0.77-2.53; $489 € /$ year, CI 281-924). The overall differences in costs (\%) and the effectiveness measures that were estimated for formoterol and salbutamol treatment in Sweden and Spain are shown in Figure 3.

\section{DISCUSSION}

The RELIEF study meets the necessary quality requirements for a reliable cost-effectiveness analysis in general (15) and in asthma in particular $(11,16,17)$. The study utilised a sufficiently large number of patients, had a long follow-up period

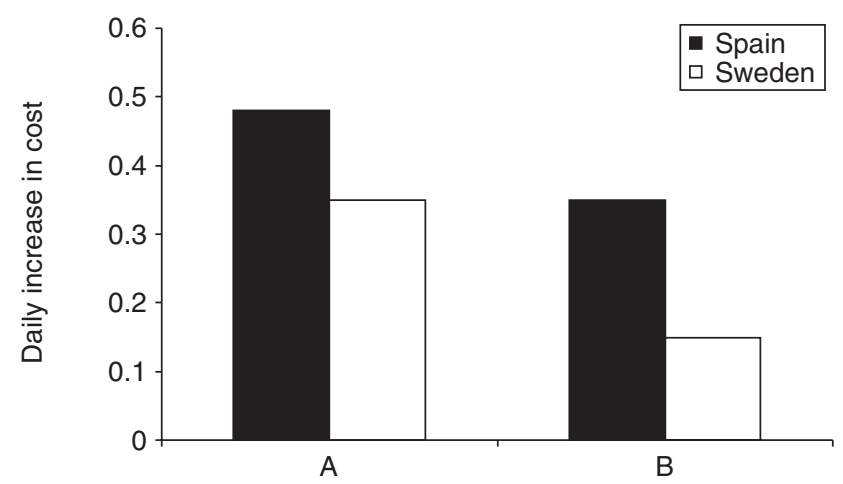

Figure 1 Summary of the difference in daily cost $(€)$ for study drug between Oxis ${ }^{\circledR}$ and Ventolin ${ }^{\circledR}$ in Spain and Sweden. (A) Study drug cost difference alone. (B) Total net daily difference in cost, including all cost offsets (other asthma medication, healthcare contacts, emergency treatment and hospitalisations) and the response rate was high. High-quality data on effectiveness and resource use could thus be obtained for each patient.

Formoterol treatment was consistently associated with a lower utilisation of resources compared with salbutamol. In terms of the overall healthcare cost, medication cost included, there were differences between and within Sweden and Spain: the two countries for which the analysis was performed. The estimated overall healthcare cost was $20 \%$ higher for formoterol in Spain. No significant difference could be detected for Sweden. This difference between Sweden and Spain largely depended on the difference in reliever treatment tradition, where Sweden uses DPIs and Spain uses pMDIs. The healthcare cost according to asthma severity shows, as expected, an increased cost for increased disease severity. Nominally, the total healthcare costs were lower for formoterol in the severe patients in Sweden. Thus, there are clearly subgroups of patients, where there are no differences in cost between formoterol and salbutamol. Furthermore, one interesting finding from this study was that the differences in cost between the treatments according to severity were fairly stable.

Health economic evaluations provide decision-makers with information on the relative cost-effectiveness of two or more treatment options. An economic evaluation may certainly adopt a societal perspective, i.e. analyse the costs and welfare effects of treatments, no matter who bears the cost or to whom the benefits accrue. It may also, as in this study, adopt a strict healthcare-payer perspective. It should be observed, however, that this perspective does not necessarily mean that the healthcare cost should be minimised. On the contrary, where the study identified an increased cost, but at the same time demonstrated significant improvements in clinical effectiveness, the incremental cost of achieving these benefits ought to be considered. The reductions in productivity costs and intangible costs, such as suffering and distress, arising from the improved asthma control of using as-needed formoterol compared with salbutamol, may reduce or even eliminate the difference in cost between the two groups. 


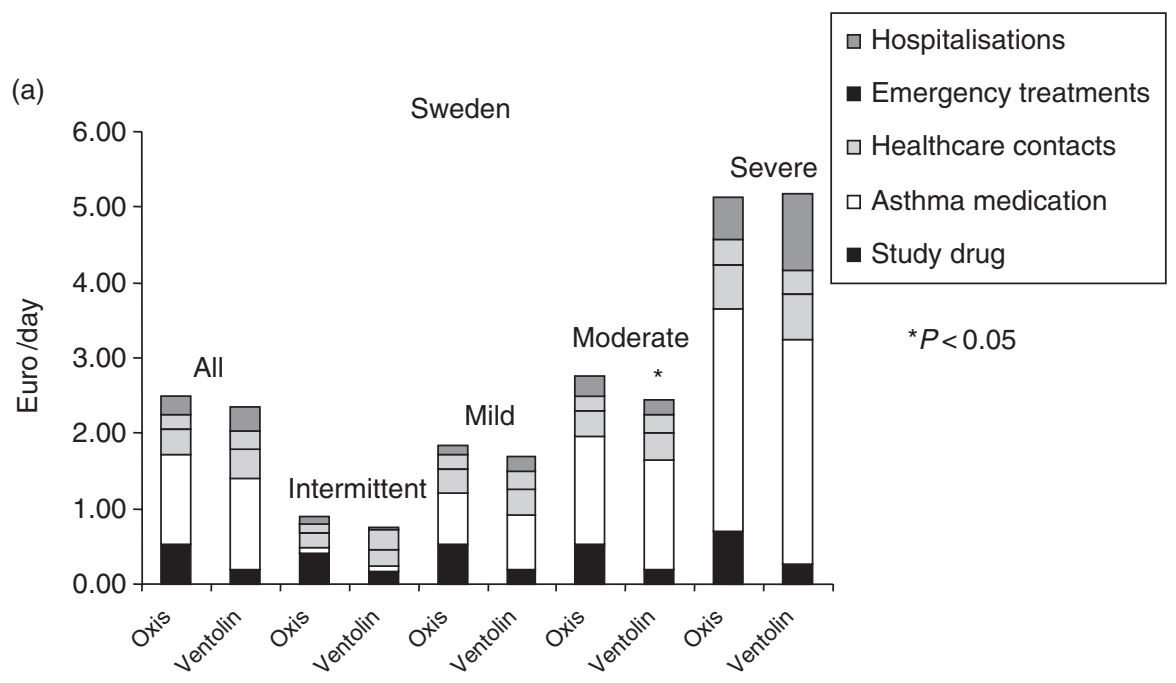

Figure 2 Total daily healthcare cost

(b)

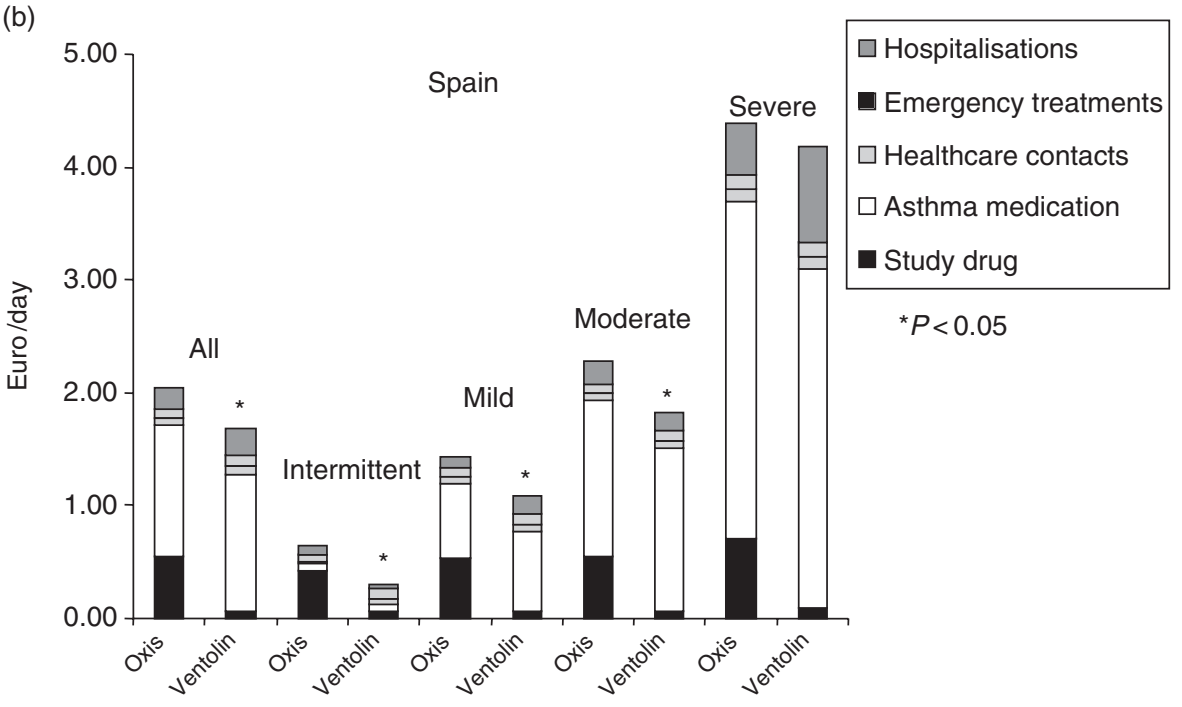
by resource item for all patients and according to disease severity for Sweden and Spain with Euro 2000 prices

ment options should include patients of all severities (11). This is obviously an attempt to provide recommendations for large studies with a real-life design to capture data on the
Figure 3 Relative costs and treatment benefits in percentages between formoterol and salbutamol. OGCS courses, oral glucocorticosteroid courses

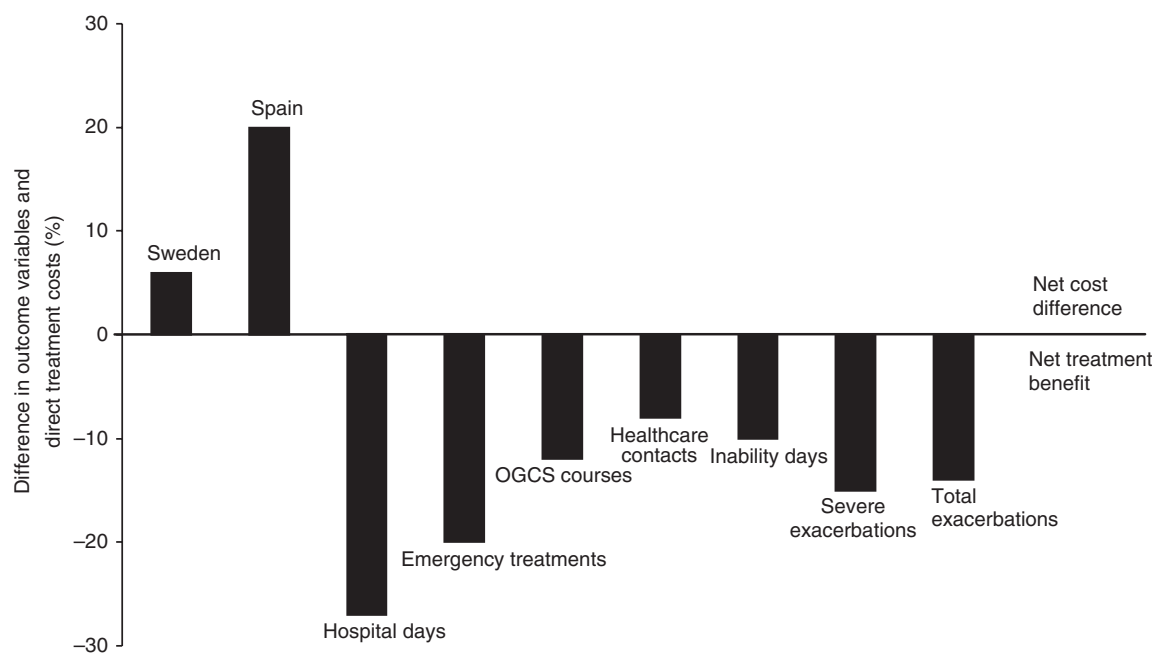


clinical effectiveness of asthma treatments. Furthermore, the increasing importance of economic evaluations in healthcare has been made even more apparent through official authorities $(20,21)$. Reviewing submitted and available health economic evaluations of asthma treatments, the National Institute of Clinical Excellence has provided recommendations on the use of inhaler devices for asthmatic children (20), and The Swedish Council on Technology Assessments in Healthcare has reviewed the published evidence of cost-effectiveness for asthma and chronic obstructive pulmonary disease treatment options (21). These two official reviews as well as academic researchers $(11,18,19)$ have found somewhat limited evidence in published studies. Hence, there is a clear demand for more robust evidence concerning the cost-effectiveness of various treatment interventions in asthma, such as that provided in the RELIEF study.

In summary, as-needed formoterol, compared with as-needed salbutamol, was associated with somewhat higher overall healthcare costs in Spain, whereas the costs were similar in Sweden. Analysing the results according to disease severity indicated that the use of as-needed formoterol was not associated with an increase in direct healthcare costs in Sweden for intermittent, mild or severe asthma, although a small increase was seen in the group with moderately severe disease. Furthermore, this analysis showed that there were no cost differences in the management of severe asthma in Spain, despite a cost increase with formoterol for other severity groups.

In conclusion, compared with salbutamol as reliever medication, formoterol produced statistically significant improvements in effectiveness, less use of reliever and maintenance medication and reduced resource utilisation, with no increase or only a limited increase in healthcare cost.

\section{ACKNOWLEDGMENTS}

The financial support from AstraZeneca R\&D Lund is gratefully acknowledged.

\section{REFERENCES}

1 Global Initiative for Asthma. Global Strategy for Asthma Management and Prevention. National Institutes of Health, National Heart, Lung and Blood Institute 1995: 1-176 (publication no. 95-3659).

2 British Thoracic Society. The British guidelines on asthma management. Thorax 1997; 52 (Suppl. 1): 1-21.

3 Svedmyr N, Löfdahl CG. Physiology and pharmacokinetics of beta-adrenergic agonists. In: Jenne JW, Murphy S, eds. Drug Therapy for Asthma. New York: Dekker, 1987: 177-211.

4 Ringdal N, Derom E, Wåhlin-Boll E, Pauwels R. Onset and duration of action of single doses of formoterol inhaled via Turbuhaler. Respir Med 1998; 92: 1017-21.
5 Pauwels RA, Campbell M, Villasante C et al. A comparison of salbutamol and formoterol as a reliever medication in asthma: a worldwide, randomised, effectiveness trial. Eur Respir J 2003; 22 (5): 787-94.

6 Banta HD, Luce BR. Health Care Technology and its Assessment. New York: Oxford University Press, 1993.

7 Gerdtham UG, Hertzman P, Jönsson B, Boman G. Impact of inhaled corticosteroids on asthma hospitalisation in Sweden 1978 to 1991. Med Care 1996; 34: 1188-98.

8 Tattersfield AE, Löfdahl CG, Postma DS et al. Comparison of formoterol and terbutaline for as-needed treatment of asthma: a randomised trial. Lancet 2001; 357: 257-61.

9 Berggren F, Ekström T. A cost-effectiveness study comparing the as-needed use of formoterol (Oxis) and terbutaline (Bricanyl) in patients with moderate to severe asthma. Respir Med 2001; 95: 753-8.

10 Hjelmgren J, Berggren F, Andersson F. Health economic guidelines - similarities, differences and some implications. Value Health 2001; 4: 225-50.

11 Sullivan SD, Weiss KB. Health economics of asthma and rhinitis. II. Assessing the value of interventions. J Allergy Clin Immunol 2001; 107: 203-10.

12 O’Byrne PM, Barnes PJ, Rodriguez-Rosisin R et al. Low dose inhaled budesonide and formoterol in mild persistent asthma. The OPTIMA randomised trial. Am J Respir Crit Care Med 2001; 164: 1392-7.

13 Efron B, Tibshirani RJ. An Introduction to the Bootstrap. New York: Chapman \& Hall, 1993.

14 Sullivan SD, Liljas B, Buxton M et al. Design and analytic considerations in determining the cost-effectiveness of early intervention in asthma from a multinational clinical trial. Controlled Clin Trials 2001; 22: 420-37.

15 Gold RG, Russell LR, Siegel JE et al. Cost-effectiveness in Health and Medicine. New York: Oxford University Press, 1996.

16 Sullivan S, Elixhauser A, Buist S, Luce BR, Eisenberg J, Weiss K. National Asthma Education and Prevention Program, working group report on the cost effectiveness of asthma care. Am J Respir Crit Care Med 1996; 154: S84-S95.

17 Persson U, Ghatnekar O. Cost-effectiveness analysis of inhaled corticosteroids in asthma. A review of the analytical standards. Respir Med 2003; 97: 1-11.

18 Molken MP, van Doorslaer EK, Rutten FF. Economic appraisal of asthma and COPD care: a literature review 1980-1991. Soc Sci Med 1992; 35: 161-75.

19 Bryan S, Buxton MJ. Economic evaluation of treatments for respiratory disease. Pharmacoeconomics 1992; 2: 207-18.

20 The National Institute of Clinical Excellence. Clinical and cost effectiveness of inhaler devices for children with chronic asthma. NHS R\&D HTA Programme, 2000 (available at http://www. nice.org.uk).

21 Behandling av asthma och KOL. En systematisk kunskapssammanställning (in Swedish; Treatment of asthma and COPD. A systematic review). Statens beredning för medicinsk utvärdering. Stockholm: The Swedish Council on Technology Assessments in Health Care, Redners, 2000.

Paper received January 2004, accepted July 2004 